\title{
A promising treatment of tracheal stenosis in critically ill patients
}

\author{
Maria Vargas $^{1} \cdot$ Annachiara Marra $^{1} \cdot$ Pasquale Buonano ${ }^{1} \cdot$ Carmine lacovazzo $^{1} \cdot$ Giuseppe Servillo $^{1}$
}

Received: 19 February 2020 / Accepted: 26 February 2020 / Published online: 9 March 2020

(c) The Japanese Association for Thoracic Surgery 2020

\section{Dear Editor,}

We read with great interest the article by Fiorelli et al. about the use of Ciaglia Blue Dolphin (CBD) kit (Cook, Medical, Bloomington, USA) for percutaneous dilation tracheostomy (PDT) in the treatment of tracheal stenosis under the tracheotomy tube [1]. We appreciate the innovative approach of this procedure, since tracheal stenosis often requires a surgical repair [1].

Tracheal stenosis has been claimed to be a serious complication of tracheostomy with a low and comparable incidence with PDT techniques and surgical tracheostomy [2]. Tracheal stenosis mainly occurs when the tracheostomy tube is in place for a long period of time, and we know from current literature that $10 \%$ of tracheostomized patients have the tracheostomy tube in place at 1-year follow-up [3]. CBD kit (Cook, Medical, Bloomington, USA) has a modified angioplasty balloon to dilate the trachea, this kit is used for $10 \%$ of PDT worldwide [4, 5]. In the article by Fiorelli et al., the balloon was inflated with saline solution to 11 atmospheres, and the dilation of the stenosis was repeated 2 or 3 times for 15-30 s each, while the patient was ventilated by a laryngeal mask airway (LMA) with a video-broncoscope inside [1]. This means that the tracheal lumen was completely occluded during the dilation for a period of time ranging from 30 to $90 \mathrm{~s}$, while the video bronchoscope partially occluded the lumen of the LMA through the entire procedure [1]. The presence of the bronchoscope in the LMA, as well as in the endotracheal tube, reduces the diameter available for patients' ventilation [6] and this is responsible of a decrease of the delivered tidal volume, an increase of airway pressure

This comment refers to the article available online at https://doi. org/10.1007/s11748-020-01311-8

\footnotetext{
Maria Vargas

vargas.maria82@gmail.com

1 Department of Neurosciences, Reproductive and Odontostomatological Sciences, University of Naples

"Federico II", via Pansini, 80100 Naples, Italy
}

and of respiratory acidosis [7]. Furthermore, the complete occlusion of the tracheal lumen, even from 30 to $90 \mathrm{~s}$, in critically ill patients with stridor and respiratory distress may be responsible of serious desaturation and life-threating situations. Our concerns are about the previous points. Since the use of CBD kit may be promising as a treatment of tracheal stenosis in critically ill patients, we appreciate a lot if the authors may provide (1) the incidence of the desaturations occurred during the procedure, (2) more details about the airway management and (3) the settings of mechanical ventilation if used. Furthermore, it is not clear to us if the procedure was performed as urgent or elective since the serious condition of the patients.

\section{References}

1. Fiorelli A, Bove M, Noro A, Iuorio A, Santini M, Ferraro F. Dilation of tracheal stenosis below tracheostomy tube with Dolphin percutaneous tracheostomy kit. Gen Thorac Cardiovasc Surg. 2020. https://doi.org/10.1007/s11748-020-01311-8.

2. Putensen C, Theuerkauf N, Guenther U, et al. Percutaneous and surgical tracheostomy in critically ill adult patients: a meta-analysis. Crit Care. 2014;18:544.

3. Vargas M, Sutherasan Y, Brunetti I, Micalizzi C, Insorsi A, Ball $\mathrm{L}$, et al. Mortality and long-term quality of life after percutaneous tracheotomy in Intensive Care Unit: a prospective observational study. Minerva Anestesiol. 2018;9:1024-31.

4. Vargas M, Sutherasan Y, Antonelli M, Brunetti I, Corcione A, Laffey JG, et al. Tracheostomy procedures in the intensive care unit: an international survey. Crit Care. 2015;19:291-301.

5. Vargas M, Servillo G, Arditi E, et al. Tracheostomy in Intensive Care Unit: a national survey in Italy. Minerva Anestesiol. 2013;79:156-64.

6. Vargas M, Servillo G, Tessitore G, Aloj F, Brunetti I, Arditi E, et al. Double lumen endotracheal tube for percutaneous tracheostomy. Respir Care. 2014;59:1652-9.

7. Vargas M, Servillo G, Tessitore G, Aloj F, Brunetti I, Arditi E, et al. Percutaneous dilatational tracheostomy with a double-lumen endotracheal tube. A comparison of feasibility, gas exchange, and airway pressures. Chest. 2015;147:1267-74.

Publisher's Note Springer Nature remains neutral with regard to jurisdictional claims in published maps and institutional affiliations. 